\title{
Effects of erythropoiesis-stimulating agents on heart failure patients with anemia: a meta-analysis
}

\author{
Hengliang Zhang ${ }^{1}$, Pei Zhang ${ }^{1}$, Yaheng Zhang ${ }^{1}$, Junqiang Yan $^{1}$, Pingshuan Dong ${ }^{1}$, Yanyu Wang ${ }^{1}$, Xiaowei Niu ${ }^{2}$ \\ ${ }^{1}$ Department of Cardiology, The First Affiliated Hospital, and College of Clinical Medicine of Henan University of Science and Technology, \\ Luoyang, China \\ ${ }^{2}$ The First College of Clinical Medical, Lanzhou University, Lanzhou, China
}

Adv Interv Cardiol 2016; 12, 3 (45): 247-253

DOI: 10.5114 /aic.2016.61647

\begin{abstract}
A bstract
Introduction: Heart failure (HF) is always complicated with anemia and is associated with bad prognosis in this patient population. Several studies have assessed the potential role of erythropoietin-stimulating agent (ESA) in improving cardiac function and reducing the number of hospitalizations in anemic patients with $\mathrm{HF}$.

Aim: We performed a meta-analysis to assess the potential role of ESA in the treatment of anemic patients with HF.

Material and methods: A literature and Medline search was performed to identify studies with control groups that examined the efficacy of ESA therapy in patients with $\mathrm{HF}$ and anemia.

Results: A total of 11 studies were included ( $n=3044$ subjects) in the final analysis. Compared to placebo, ESA therapy was associated with increased hemoglobin levels $(1.89 \mathrm{~g} / \mathrm{dl} ; 95 \% \mathrm{Cl}: 1.64-2.14, p<0.00001)$, increased left ventricular ejection fraction (LVEF) to 6.88 (95\% Cl: 0.49-13.28, $p=0.03)$, decreased B-type natriuretic protein $(-272.20 ; 95 \% \mathrm{Cl}:(-444.52)-(-99.89), p=0.002)$, improvement in New York Heart Association functional class to -0.33 mean difference $(95 \% \mathrm{Cl}:(-0.44)-(-0.23), p<0.00001)$, and decreased hospitalization ( $\mathrm{OR}=0.61,95 \% \mathrm{Cl}: 0.39-0.94, p=0.02)$. There was no significant between-group difference in all-cause mortality $(\mathrm{OR}=0.78,95 \% \mathrm{Cl}: 0.51-1.21, p=0.27)$.

Conclusions: The treatment of anemia with ESA therapy did not reduce the rate of all-cause mortality among patients with heart failure, but ESA therapy made a potential important contribution to patients' symptomatic improvement.
\end{abstract}

Key words: meta-analysis, heart failure, randomized controlled trials, anemia, erythropoietin-stimulating agents.

\section{Introduction}

Heart failure (HF) is always complicated with anemia and is associated with bad prognosis in this patient population. Depending on the definition used and specific patient population studied, the prevalence rate of anemia in HF patients widely varies from $9 \%$ to $70 \%$ [1-4]. In a metaanalysis of HF patients, presence of anemia almost doubled the mortality risk [5]. Anemia in HF patients not only causes a higher mortality rate, but is also associated with higher rate of various morbidities such as increased number of hospitalizations [6], worse New York Heart Association (NYHA) functional class [7], worse exercise capacity [8], cognitive impairment [9], and reduced quality of life [10].

The safety of erythropoiesis-stimulating agent (ESA) therapy in patients with renal failure and malignancies is not confirmed, but this is an effective therapy of anemia in chronic kidney disease (CKD) and cancer [11, 12]. Erythropoiesis-stimulating agent therapy can improve the health-related quality of life (HRQL) and fatigue of patients with CKD and cancer, and this improvement is both statistically and clinically significant [13]. Several studies have explored the potential therapeutic effects of ESA in improving heart function and reducing the hospitalization rate in patients with HF. Other studies, however, have shown that HF patients have higher levels of erythropoietin, which may lead to higher mortality [14].

\section{Aim \\ We performed a meta-analysis to assess the potential role of ESA in the treatment of anemic patients with HF. \\ Material and methods \\ Search strategy \\ The electronic databases MEDLINE, EMBASE, the Co- chrane Central Registry of Controlled Trials, and the Web of Science were searched from inception to July 2015.}

\section{Corresponding author:}

Hengliang Zhang MD, PhD, Department of Cardiology, The First Affiliated Hospital of Henan University of Science and Technology, Jinghua St, 471000 Luoyang, China, fax: +86 13937959952, e-mail: 271674835@qq.com

Received: 27.10.2015, accepted: 21.12.2015. 
This search included the following terms: "heart failure", "congestive heart failure", "chronic heart failure", "CHF", "darbepoetin", "erythropoiesis", "stimulating proteins", "erythropoiesis stimulating protein", "recombinant erythropoietin", "EPO/erythropoietin" and "randomized controlled trials". The search was limited to English language articles of studies in adult humans. We also hand-searched potentially relevant studies, investigated registers of ongoing trials, and contacted the lead authors if necessary.

\section{Study selection criteria}

Two investigators (H.L.Z. and P.Z.) searched and evaluated all titles, abstracts and full articles independently using predesigned inclusion and exclusion criteria. Any uncertainties were resolved by consensus or consultation with the third investigator (J.Q.Y.) if necessary, which was infrequent. We excluded studies that 1) concerned non-clinical research; 2) included subjects without HF; 3) included subjects without anemia; 4) did not involve the administration of erythropoietin or darbepoetin; 5) in-

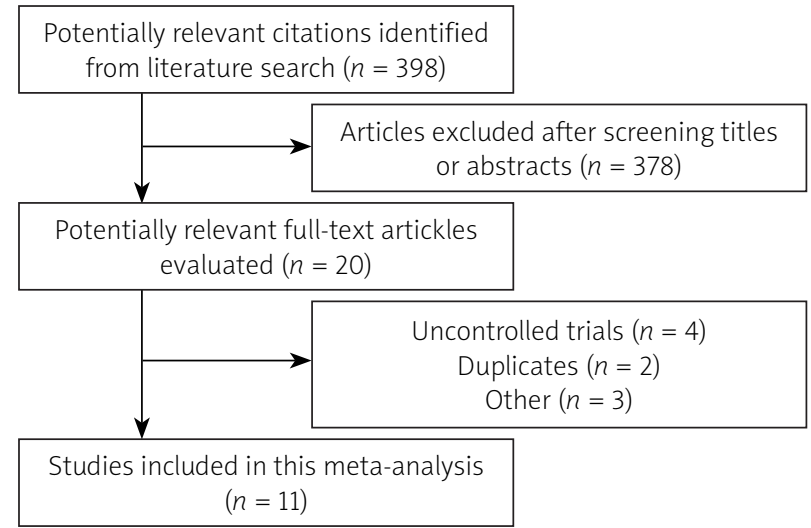

Figure 1. Process of study selection. Flowchart shows the literature search process and the final number of studies included cluded patients less than 18 years old; 6) were published in abstract form only; 7) were not published in English.

\section{Statistical analysis}

The study was conducted following Cochrane Collaboration meta-analysis review methodology, and data analysis was performed with the RevMan 5.3 and STATA 12.0 software package. Continuous variables with normal distribution are presented as mean \pm standard deviation (SD). When studies did not directly supply the SD of the mean for the calculation of effect size, it was manually calculated from the standard error (SE) or the $95 \%$ confidence interval $(\mathrm{Cl})$. Treatment effects for continuous variables were evaluated as weighted mean difference (WMD). We pooled the results from the individual studies and performed tests of heterogeneity between studies using the $\chi^{2}$ test and quantified by the $R^{2}$ statistic. When significant heterogeneity was detected between studies, the random effects model was used. Possible publication bias was estimated with a funnel plot and Egger's test. Meta-regression analyses were performed to explore the potential sources of significant heterogeneity. To reduce the risk of over-fitting of the regression model, a minimum of nine studies was set to identify each influential factor.

\section{Results}

The primary electronic search yielded 398 studies. After screening the titles and abstracts, 20 articles were retrieved for full-text assessment. According to the inclusion criteria, 9 articles were excluded and a total of 11 studies [15-25] were included (Figure 1). All of those studies were published in full-text form.

\section{Study characteristics}

This meta-analysis include 11 studies comprising 3044 patients, and the characteristics of those studies

Table I. Characteristics of included studies

\begin{tabular}{|c|c|c|c|c|c|c|c|}
\hline \multirow{2}{*}{$\begin{array}{l}\text { Study (first } \\
\text { author, year) }\end{array}$} & \multirow[t]{2}{*}{$N$} & \multicolumn{2}{|c|}{ Age [years] } & \multirow{2}{*}{$\begin{array}{c}\text { Anemia definition, } \\
\text { hemoglobin level }[\mathrm{g} / \mathrm{dl}]\end{array}$} & \multicolumn{2}{|c|}{ ESA therapy } & \multirow{2}{*}{$\begin{array}{l}\text { Follow-up } \\
\text { [months] }\end{array}$} \\
\hline & & ESA & Control & & ESA & Control & \\
\hline Cleland, 2005 & 24 & 69 & 74 & $<12.5$ & DA & Placebo & 2 \\
\hline Ghali, 2008 & 319 & 68 & 69 & $9-12$ & $\mathrm{DA}+$ iron & Placebo + iron & 12 \\
\hline Kaurea, 2008 & 41 & 73 & 65 & $<12.5$ & $\mathrm{DA}+$ iron & Placebo + iron & 3 \\
\hline Mancini, 2003 & 23 & 87 & 63 & Hematocrit < 35\% & EPO + iron & Placebo + iron & 3 \\
\hline Palazzuoli, 2006 & 38 & 72 & 75 & $<11$ & EPO + iron & Placebo + iron & 9 \\
\hline Palazzuoli, 2007 & 51 & 74 & 72 & $<11.5$ & EPO + iron & Placebo + iron & 8 \\
\hline Parissis, 2008 & 32 & 72 & 69 & $<12.5$ & $\mathrm{DA}+$ iron & Placebo + iron & 3 \\
\hline Ponikowski, 2007 & 41 & 70 & 72 & $9-12$ & DA + iron & Placebo + iron & 6 \\
\hline Silverberg, 2001 & 32 & 75 & 72 & $10-11.5$ & EPO + iron & Iron & 8 \\
\hline Swedberg, 2013 & 2278 & 71 & 72 & $9-12$ & DA + iron & Placebo + iron & 28 \\
\hline Veldhuisen, 2007 & 165 & 71 & 71 & $9-12$ & $\mathrm{DA}+$ iron & Placebo + iron & 6 \\
\hline
\end{tabular}

EPO - erythropoietin, DA - darbepoetin alfa, ESA - erythropoiesis-stimulating agent. 
are summarized in Table I. Of those patients, 1564 received ESA therapy and 1480 were in the control group. Baseline characteristics of the two study groups were well balanced and no significant differences were reported. All of the participants had typical symptoms of heart failure with left ventricular ejection fraction (LVEF) $<40 \%$. The baseline hemoglobin level ranged from 9.0 to $12.5 \mathrm{~g} / \mathrm{dl}$. The type of ESA therapy is darbepoetin alfa or erythropoietin. The dose regimen and target hemoglobin level were variable.

\section{Therapeutic effects of erythropoiesis- stimulating agent}

Nine studies provided data on the effect of ESA therapy on hemoglobin levels with an average increase of $1.89 \mathrm{~g} / \mathrm{dl}(95 \% \mathrm{Cl}: 1.64-2.14, p<0.00001)$ compared to placebo (Figure 2 A). Five studies comprising 321 participants reported left ventricular ejection fraction at baseline and after ESA treatment, and the overall beneficial change was 6.88 (95\% Cl: 0.49-13.28, $p=0.03$; Figure $2 \mathrm{~B}$ ). In three studies, administration of ESA therapy was correlated with a decrease in B-type natriuretic protein (BNP) levels, with a mean change of $-272.20(95 \% \mathrm{Cl}$ : (-444.52)-(-99.89), $p=0.002$; Figure $2 \mathrm{C})$. The use of ESA therapy led to an improvement in NYHA functional class in five studies and the mean difference was -0.33 (95\% Cl: (-0.44)-(-0.23), $p<0.00001$; Figure 2 D). With regard to the type of exercise test, ESA therapy compared with control improved 6-minute walk distance (6-MWD) by $81.48 \mathrm{~m} \mathrm{(95 \%} \mathrm{Cl:} \mathrm{14.57-148.39,}$ $p=0.02$; Figure $2 \mathrm{E}$ ), exercise duration by $79.12 \mathrm{~s}$ (95\% Cl: 14.53-143.72, $p=0.02$; Figure $2 \mathrm{~F}$ ), and peak

A. Comparison of hemoglobin

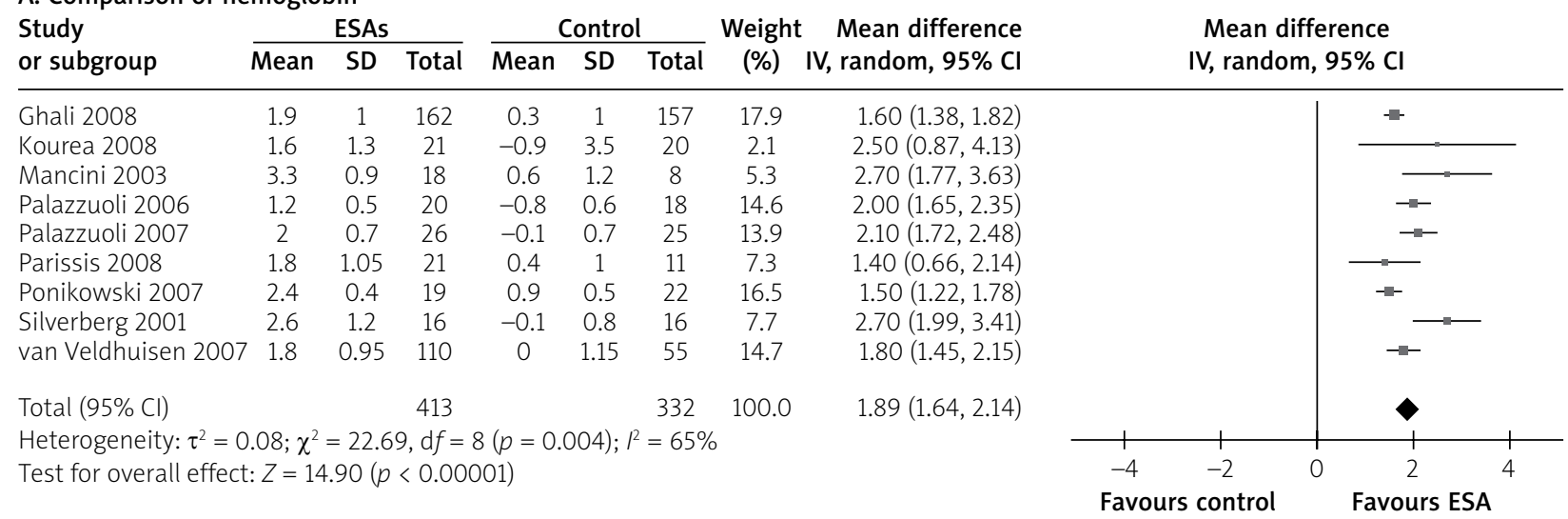

B. Comparison of LVEF

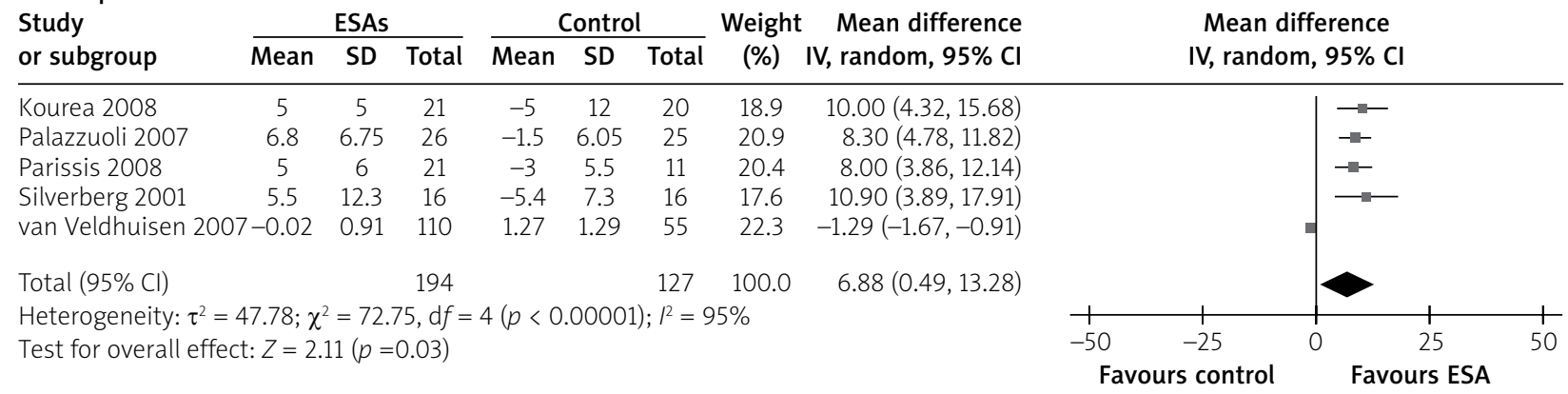

C. Comparison of BNP

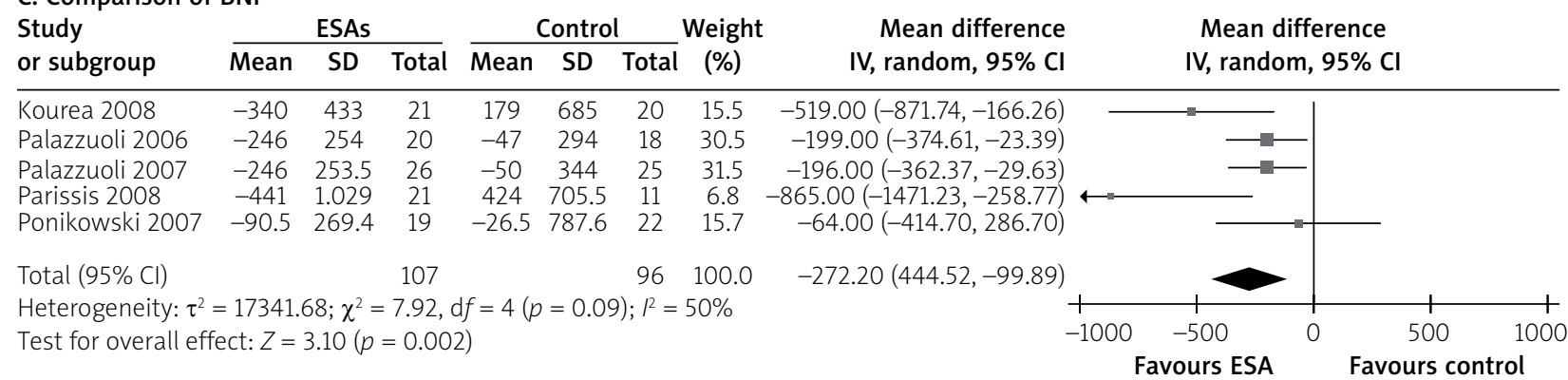

Figure 2. Effects of erythropoiesis-stimulating agent therapy in heart failure patients with anemia at follow-up compared to baseline 
D. Comparison of NYHA functional class

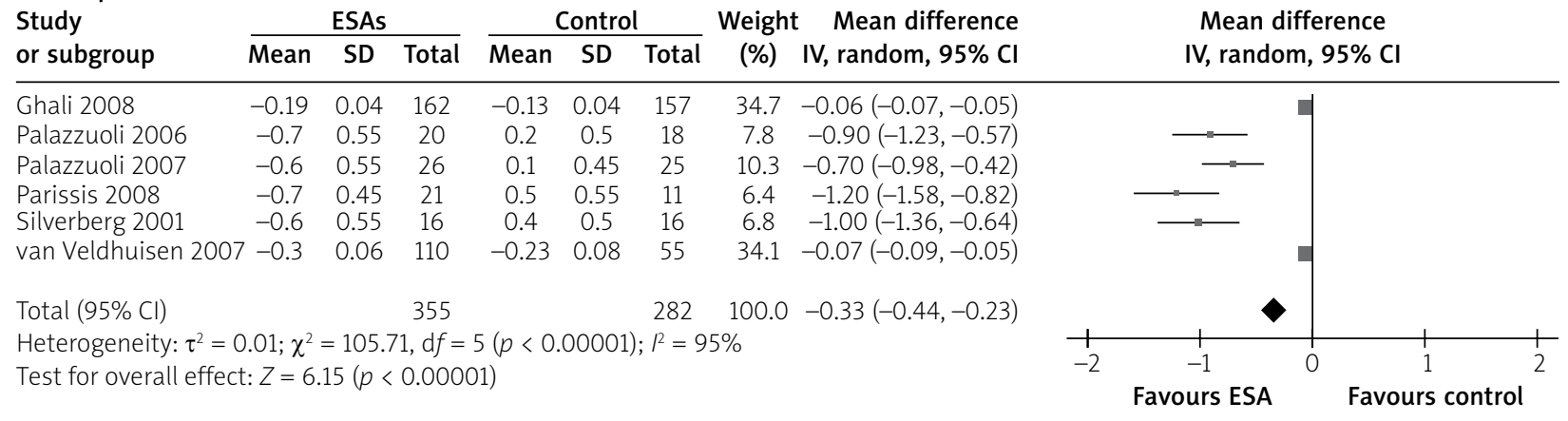

E. Comparison of 6-minute hall walk

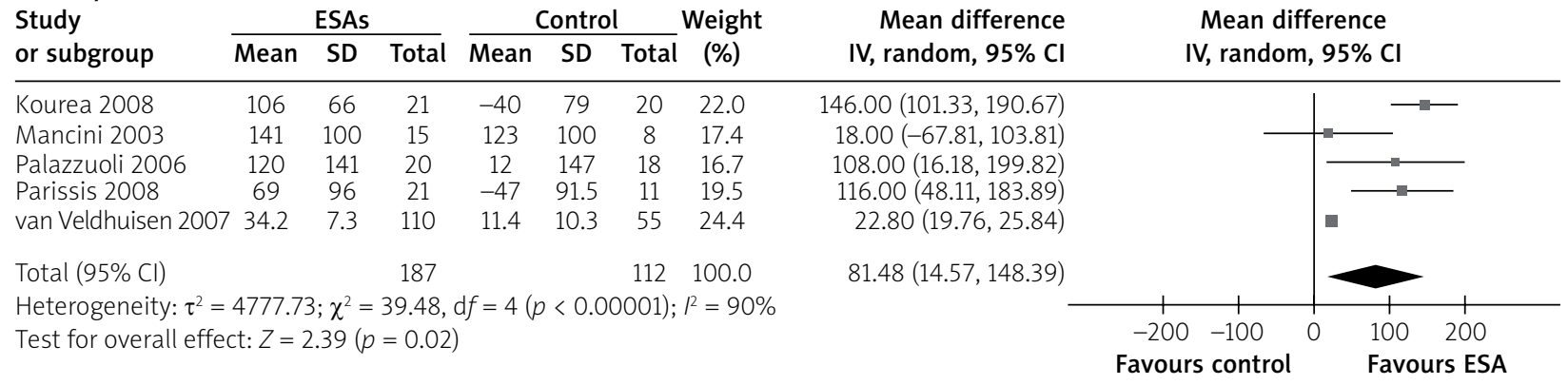

F. Comparison of exercise duration

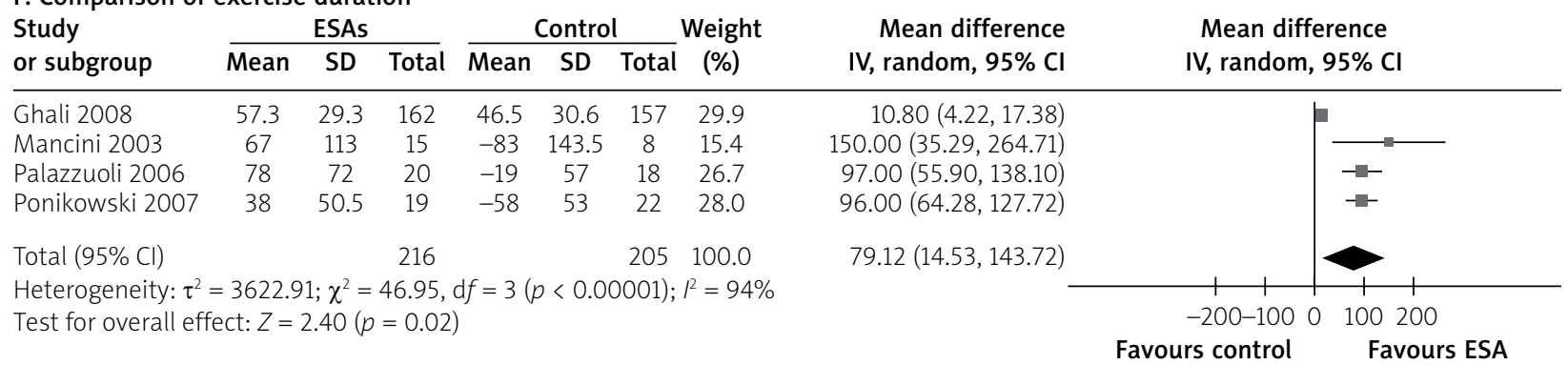

G. Comparison of peak oxygen consumption

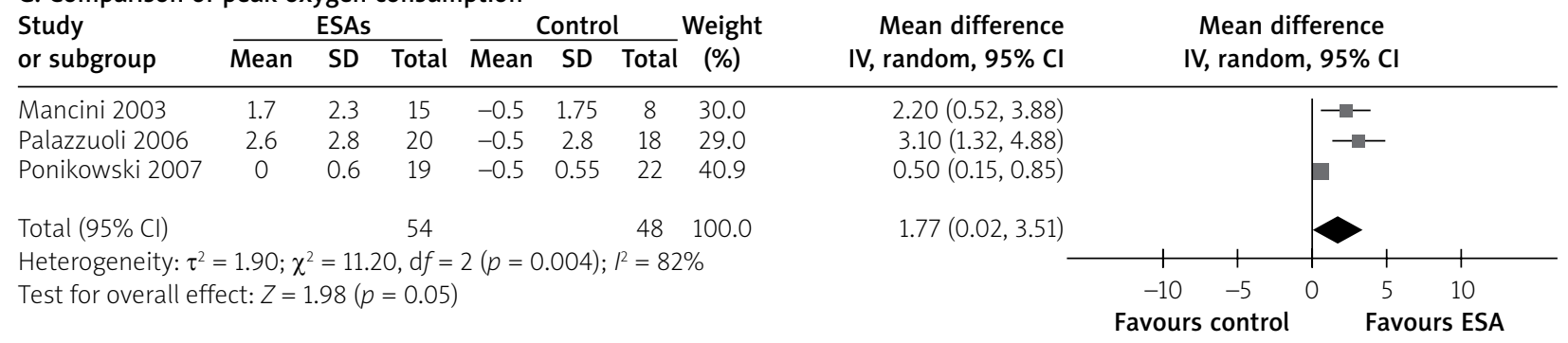

Figure 2. Cont.

oxygen consumption $\left(\mathrm{VO}_{2}\right)$ by $1.77 \mathrm{ml} / \mathrm{kg} / \mathrm{min}(95 \% \mathrm{Cl}$ : $0.02-3.21, p=0.05$; Figure $2 \mathrm{G}$ ).

\section{Hospitalizations and all-cause mortality}

The hospitalization analysis demonstrated a significant protective effect in the ESA treatment group compared with the control group (OR $=0.61,95 \% \mathrm{Cl}$ : $0.39-0.94, p=0.02$; Figure $3 \mathrm{~A}$ ), but there was no signif- icant reduction in all-cause mortality $(\mathrm{OR}=0.78,95 \% \mathrm{Cl}$ : $0.51-1.21, p=0.27$; Figure $3 \mathrm{~B}$ ).

\section{Potential sources of heterogeneity analysis}

A random-effect univariate meta-regression analysis for the hemoglobin level change, hospitalizations and allcause mortality in heart failure was conducted to explore the potential sources of heterogeneity. Data on the age, 


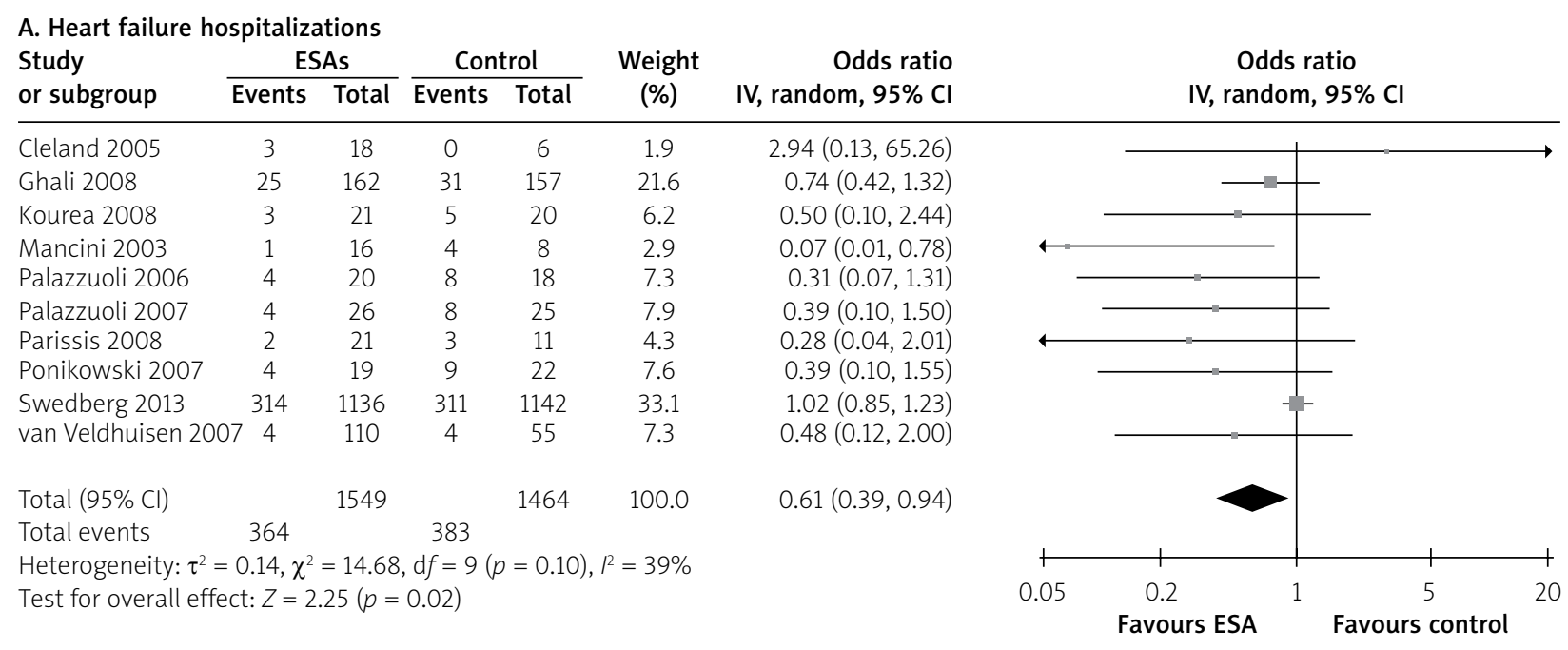

B. All-cause mortality

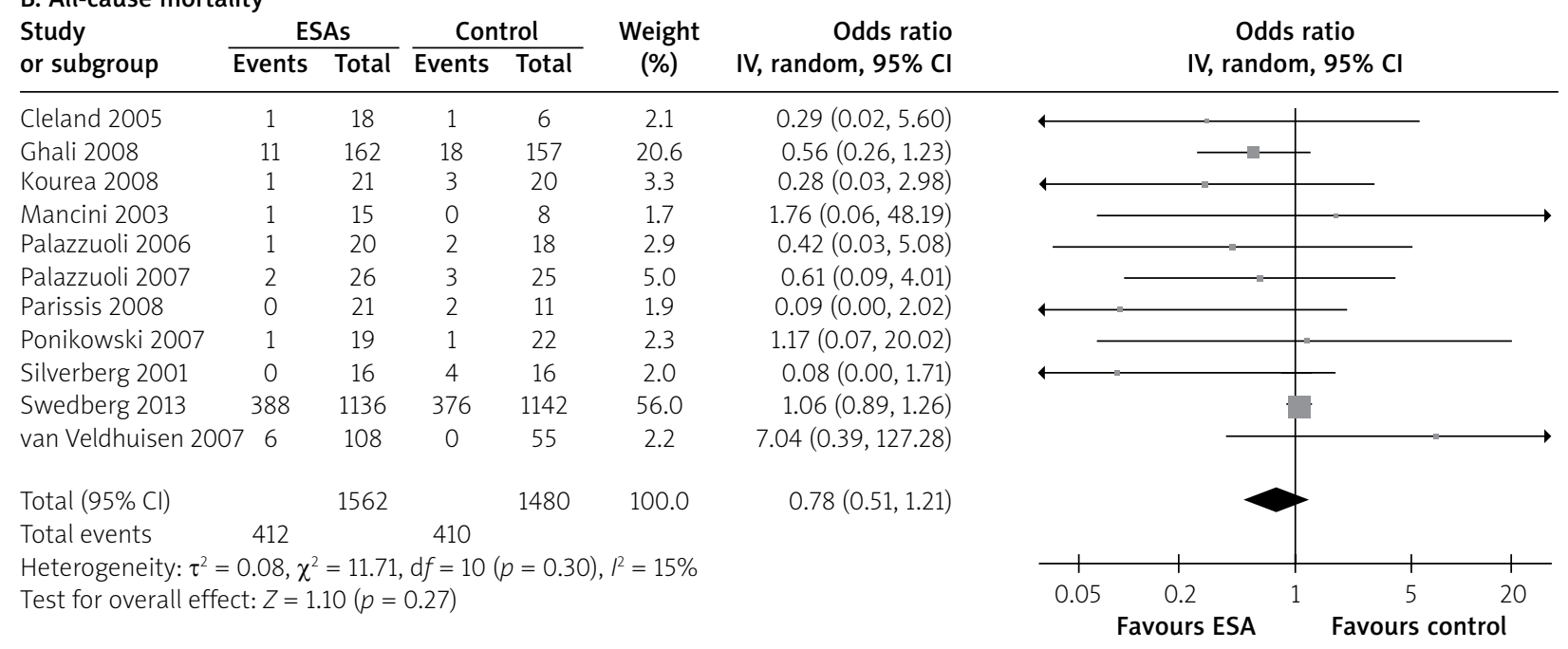

Figure 3. Effect of erythropoiesis-stimulating agent therapy on hospitalizations and mortality

sex (\% male), baseline EF, baseline hemoglobin and ESA therapy (DA or EPO) were included. As a result, baseline hemoglobin was the major heterogeneity source identified for hemoglobin level change (adjusted $R^{2}=0.21$, $p=0.089$ ). The ESA therapy was the major heterogeneity source identified for hospitalizations (adjusted $R^{2}=0.28$, $p=0.093$ ) and all-cause mortality (adjusted $R^{2}=0.23$, $p=0.035$ ). Age, sex and baseline EF may not contribute to the source of heterogeneity for hemoglobin level change, hospitalizations and all-cause mortality $(p>0.1)$.

\section{Discussion}

Anemia in HF is related to adverse clinical outcomes, but little is known about the effects of its treatment with ESA on cardiac dimensions and function. Heart failure is associated with elevated pro-inflammatory cytokines, which cause not only decreased erythropoietin (EPO) production, but also resistance to its actions on bone marrow [26, 27]. Erythropoietin levels in HF patients are lower than expected, which is possibly attributed to the action of pro-inflammatory cytokines [26, 28]. Chronic kidney disease or milder forms of renal dysfunction are also common in HF patients, and may contribute to decreased EPO production. Other factors such as inflammation, diabetes, hemo-dilution, gastrointestinal malabsorption and blood loss, absolute and functional iron deficiency, and drugs such as angiotensin receptor blockers (ARB) and angiotensin-converting enzyme inhibitors (ACEI) are believed to contribute to the development of anemia in this patient population [29]. Previous studies have shown that ESA therapy can improve heart function, exercise capacity, and quality of life in HF patients with anemia. However, because of some deficiencies such as small sample sizes and lack of double-blind and/or placebo-controlled design in those studies, no very definite conclusions could be drawn.

In this meta-analysis of 11 RCTs with 3044 patients, we found that ESA therapy leads to a significant improvement in LVEF and BNP compared with placebo. Also we 
found that ESA therapy reduced the NYHA functional class, an effect that was partly associated with patient symptomatic improvement. The specific mechanism of the improvement is not very clear. Previous studies have shown that ESA therapy seems to have potential effects to enhance cardiac contractile function and improve cardiac remodeling through its angiogenic and anti-apoptotic properties [30, 31].

Our meta-analysis found that the ESA therapy approach leads to a significant improvement in exercise capacity assessed by 6-MWD, exercise duration, and peak $\mathrm{VO}_{2}$. There are a number of potential mechanisms such as the treatment of anemia, attenuation of peripheral hypoxia with the concomitant improvement of metabolic status of peripheral muscles and the reduction of volume overloading which may explain the beneficial effects of ESA on exercise tolerance and quality of life in anemic HF patients [17].

As compared with placebo, ESA therapy led to a significant increase in hemoglobin levels and reduction in hospitalizations. However, we found that ESA therapy was not associated with a significant reduction in allcause mortality compared with placebo. This observation is partly in agreement with the previous studies [32], which suggest that ESA therapy can improve the symptoms of heart failure but does little to reduce allcause mortality.

Despite employing a random effects model, statistical heterogeneity in the present study was considerable. There are many factors contributing to heterogeneity, such as the baseline disease severity, eligibility criteria, the patient selection and randomization, differences in trial designs, the inclusion of different interventions, the follow-up in the trials and differences in sample size. All of these factors lead to increase in heterogeneity.

\section{Conclusions}

We found that the treatment of anemia with ESA therapy did not reduce the rate of all-cause mortality among patients with heart failure. However, a trend of lower BNP, higher LVEF, reduction in hospitalizations and improvement in NYHA functional class was observed. At the same time, ESA therapy led to an increase of exercise tolerance. Consequently, our findings suggest that treatment of anemia with ESA improved the symptoms of heart failure but did not improve clinical outcomes.

\section{Acknowledgments}

Hengliang Zhang and Pei Zhang contributed equally to this work.

\section{Conflict of interest}

The authors declare no conflict of interest.

\section{References}

1. Lindenfeld J. Prevalence of anemia and effects on mortality in patients with heart failure. Am Heart J 2005; 149: 391-401.

2. Ghali JK. Anemia and heart failure. Curr Opin Cardiol 2009; 24: 172-8.

3. Caira C, Ansalone G, Mancone M, et al. Heart failure and iron deficiency anemia in Italy: results from CARMES-1 registry. Future Cardiol 2013; 9: 437-44.

4. Beutler E, Waalen J. The definition of anemia: what is the lower limit of normal of the blood hemoglobin concentration? Blood 2006; 107: 1747-50.

5. Groenveld HF, Januzzi JL, Damman K, et al. Anemia and mortality in heart failure patients a systematic review and meta-analysis. J Am Coll Cardiol 2008; 52: 818-27.

6. Salisbury AC, Kosiborod M. Outcomes associated with anemia in patients with heart failure. Heart Fail Clin 2010; 6: 359-72.

7. Horwich TB, Fonarow GC, Hamilton MA, et al. Anemia is associated with worse symptoms, greater impairment in functional capacity and a significant increase in mortality in patients with advanced heart failure. J Am Coll Cardiol 2002; 39: 1780-6.

8. Kalra PR, Bolger AP, Francis DP, et al. Effect of anemia on exercise tolerance in chronic heart failure in men. Am J Cardiol 2003; 91 : 888-91.

9. Zuccala G, Marzetti E, Cesari M, et al. Correlates of cognitive impairment among patients with heart failure: results of a multicenter survey. Am J Med 2005; 118: 496-502.

10. Adams KF Jr, Pina IL, Ghali JK, et al. Prospective evaluation of the association between hemoglobin concentration and quality of life in patients with heart failure. Am Heart J 2009; 158: 965-71.

11. Unger EF, Thompson AM, Blank MJ, et al. Erythropoiesis-stimulating agents: time for a reevaluation. N Engl J Med 2010; 362: 189-92.

12. Phrommintikul A, Haas SJ, Elsik M, et al. Mortality and target haemoglobin concentrations in anaemic patients with chronic kidney disease treated with erythropoietin: a meta-analysis. Lancet 2007; 369: 381-8.

13. Kimel M, Leidy NK, Mannix S, et al. Does epoetin alfa improve health-related quality of life in chronically ill patients with anemia? Summary of trials of cancer, HIV/AIDS, and chronic kidney disease. Value Health 2008; 11: 57-75.

14. van der Meer P, Lok DJ, Januzzi JL, et al. Adequacy of endogenous erythropoietin levels and mortality in anaemic heart failure patients. Eur Heart J 2008; 29: 1510-5.

15. Cleland JG, Sullivan JT, Ball S, et al. Once-monthly administration of darbepoetin alfa for the treatment of patients with chronic heart failure and anemia: a pharmacokinetic and pharmacodynamic investigation. J Cardiovasc Pharmacol 2005; 46: 155-61.

16. Ghali JK, Anand IS, Abraham WT, et al. Randomized double-blind trial of darbepoetin alfa in patients with symptomatic heart failure and anemia. Circulation 2008; 117: 526-35.

17. Kourea K, Parissis JT, Farmakis D, et al. Effects of darbepoetin-alpha on quality of life and emotional stress in anemic patients with chronic heart failure. Eur J Cardiovasc Prev Rehabil 2008; 15: 365-9.

18. Mancini DM, Katz SD, Lang CC, et al. Effect of erythropoietin on exercise capacity in patients with moderate to severe chronic heart failure. Circulation 2003; 107: 294-9.

19. Palazzuoli A, Silverberg D, lovine F, et al. Erythropoietin improves anemia exercise tolerance and renal function and reduces B-type natriuretic peptide and hospitalization in patients with heart failure and anemia. Am Heart J 2006; 152: 1096 e9-15. 
20. Palazzuoli A, Silverberg DS, lovine F, et al. Effects of beta-erythropoietin treatment on left ventricular remodeling, systolic function, and B-type natriuretic peptide levels in patients with the cardiorenal anemia syndrome. Am Heart J 2007; 154: 645 e9-15.

21. Parissis JT, Kourea K, Panou F, et al. Effects of darbepoetin alpha on right and left ventricular systolic and diastolic function in anemic patients with chronic heart failure secondary to ischemic or idiopathic dilated cardiomyopathy. Am Heart J 2008; 155: 751 e1-7.

22. Ponikowski P, Anker SD, Szachniewicz J, et al. Effect of darbepoetin alfa on exercise tolerance in anemic patients with symptomatic chronic heart failure: a randomized, double-blind, placebo-controlled trial. J Am Coll Cardiol 2007; 49: 753-62.

23. Silverberg DS, Wexler D, Sheps D, et al. The effect of correction of mild anemia in severe, resistant congestive heart failure using subcutaneous erythropoietin and intravenous iron: a randomized controlled study. J Am Coll Cardiol 2001; 37: 1775-80.

24. Swedberg K, Young JB, Anand IS, et al. Treatment of anemia with darbepoetin alfa in systolic heart failure. N Engl J Med 2013; 368: 1210-9.

25. van Veldhuisen DJ, Dickstein K, Cohen-Solal A, et al. Randomized, double-blind, placebo-controlled study to evaluate the effect of two dosing regimens of darbepoetin alfa in patients with heart failure and anaemia. Eur Heart J 2007; 28: 2208-16.

26. Opasich C, Cazzola M, Scelsi L, et al. Blunted erythropoietin production and defective iron supply for erythropoiesis as major causes of anaemia in patients with chronic heart failure. Eur Heart J 2005; 26: 2232-7.

27. Belonje AM, Voors AA, van Gilst WH, et al. Erythropoietin in chronic heart failure. Congest Heart Fail 2007; 13: 289-92.

28. Belonje AM, Voors AA, van der Meer P, et al. Endogenous erythropoietin and outcome in heart failure. Circulation 2010; 121 : 245-51.

29. Arora NP, Ghali JK. Anemia and iron deficiency in heart failure. Heart Fail Clin 2014; 10: 281-94.

30. van der Meer P, Lipsic E, Henning RH, et al. Erythropoietin induces neovascularization and improves cardiac function in rats with heart failure after myocardial infarction. J Am Coll Cardiol 2005; 46: 125-33.

31. Calvillo L, Latini R, Kajstura J, et al. Recombinant human erythropoietin protects the myocardium from ischemia-reperfusion injury and promotes beneficial remodeling. Proc Natl Acad Sci USA 2003; 100: 4802-6.

32. Pfeffer MA, Burdmann EA, Chen CY, et al. A trial of darbepoetin alfa in type 2 diabetes and chronic kidney disease. $N$ Engl I Med 2009; 361: 2019-32. 